\title{
Estimating the long-run relationship between income inequality and economic development
}

\author{
Tuomas Malinen \\ University of Helsinki and HECER
}

Discussion Paper No. 260

April 2009

ISSN 1795-0562

HECER - Helsinki Center of Economic Research, P.O. Box 17 (Arkadiankatu 7), FI-00014 University of Helsinki, FINLAND, Tel +358-9-191-28780, Fax +358-9-191-28781, E-mail info-hecer@helsinki.fi, Internet www.hecer.fi 


\title{
Estimating the long-run relationship between income inequality and economic development ${ }^{\star}$
}

\begin{abstract}
There are several theories describing the effect of income inequality on economic growth. These theories usually predict that there exists some optimal, steady-state growth path between inequality and development. This study uses a new measure of income distribution and panel data cointegration methods to test for the existence of such a steady-state equilibrium relation. It is shown that there is a long-run equilibrium relationship between the variables, where the effect of income inequality on growth is negative.
\end{abstract}

JEL Classification: C23, O15, 040

Keywords: Developing and developed economies, panel cointegration, panel dynamic OLS, panel dynamic SUR

Tuomas Malinen

Department of Economics

P.O. Box 17 (Arkadiankatu 7)

FI-00014 University of Helsinki

FINLAND

e-mail: tuomas.malinen@helsinki.fi

* Author is grateful to the Yrjö Jahnsson foundation for financial support. Author wishes to thank Joerg Breitung, Markku Lanne, Tapio Palokangas, Vesa Kanniainen, Leena Kalliovirta, Tanja Saxell, Antti Huotari, Henri Nyberg, and participants at the FDPE Workshop in econometrics and computational economics in Helsinki, December 2008, for comments. 


\section{Introduction}

The decades long empirical research on the relationship between income inequality and economic development has produced controversial results, with the direction and the statistical significance of the effect of income inequality on economic growth changing between studies (Banerjee \& Duflo 2003, Barro 2000, Chen 2003, Forbes 2000, Li \& Zou 1998, Lin et al. 2006). Theories have also generally been divided on the effect of income inequality on growth. The classical approach argues that saving rates are an increasing function of wealth. In this case, inequality will increase incomes of the rich whose marginal propensity to save is the highest. Thus, income inequality will lead to faster capital accumulation (Kaldor 1957, Kuznets 1955, Smith 1776). The political economy approach emphasizes the destabilizing effect that inequality may have on the society (Benhabib \& Rustichini 1996). According to this view, equality will increase stability in the society and simulate investments and economic growth. The credit market imperfection approach suggests that equality of incomes diminishes the effect of credit-constraints on human capital accumulation in developed economies (Galor \& Zeira 1993). Because credit-constraints become less binding in an developed economy where incomes are distributed evenly, equality of incomes will fasten the accumulation of human capital and thus accelerate economic growth.

Despite of several theories describing the relationship between inequality and growth, the dependence between the variables over time remains a open empirical question. Although we have observations on GDP from several consecutive years, values of commonly used Gini indexes (e.g. the Deininger and Squire's (1996) Gini index) have not been consistently measured over time, which has made it virtually impossible to assess the possible time dependence between the 
two variables. Some studies have tried to bypass this problem by regressing the values of averaged growth rates of 20 years, or more, on the values of Gini index and other explanatory variables in the first year included in the averaging (Chen 2002, Forbes 2000). The problem with this method is that these multidecade averages lose a lot of information and there is a risk of spurious parameter estimates. The observed controversy in the relation between inequality and growth has also led some to estimate the relation using non-parametric or semi-parametric methods (Banerjee \& Duflo 2003, Frazer 2006, Lin et al. 2006). The advantages of non-parametric methods are the fact that they can be used to estimate the relation between variables in both short- and long-run and robustness. The drawback of these methods is low statistical power compared to parametric methods, especially in finite samples. Recently, Galbraith and Kum (2006) have gathered a Gini index data set that has continuous observations from several countries, which enables the use of panel data time series methods.

From time series analysis we know that, if variables are integrated processes, we can learn about their long-run dependence by testing whether the variables are cointegrated. If variables are found to be cointegrated, there exists a stationary distribution between them, and we can estimate this steady-state relationship using standard estimation methods. Unfortunately, these rules do not apply to panel data per se. The inference and estimation in panel cointegrated data differs from that in regular time series, because the asymptotic properties of the estimators in panel cointegrated regression models are different from those of time series cointegrated regression models (Baltagi 2008, Phillips \& Moon 1999). The time series regression may, for example, be spurious, while the panel regression utilising all cross sections is not (Phillips \& Moon 1999). OLS estimator is also not asymptotically unbiased in cointegrated panel data (Kao \& Chiang 2000). 
This study uses panel cointegration methods and improved data on income inequality to assess the possible steady-state relationship between income inequality and economic development. According to panel unit root tests, both the logarithmic EHII2.1 Gini index and the logarithmic GDP series seem to follow an I(1) process in countries in question. ${ }^{1}$ They are also found to be cointegrated of order one using Pedroni's (2004) panel cointegration test, which implies that there is long-run equilibrium relation between them. The cointegrating coefficient of Gini index is estimated with panel dynamic OLS and panel dynamic SUR estimators and it is found to be negative.

This paper is organized as follows. Section 2 presents the general theories describing the causal relationship from income inequality to economic growth. Section 3 presents the data and section 4 report the results of panel unit root and cointegration tests. Estimation details and results are given in section 5 and section 6 concludes.

\section{The theoretical relationships between inequality and growth}

Benabou (2005) has suggested that endogeneity of income inequality in growth regressions is the primary reason for the observed controversy in empirical studies. It is quite intuitive that income of a country and the distribution of income within a country are jointly determined. This is also a prominent feature in the theories describing the relationship between inequality and development. Three main theoretical linkages between inequality and growth are presented here: the classical income approach, the combined credit-market imperfections approach,

\footnotetext{
${ }^{1}$ EHII=Estimated Household Income Inequality Data Set by University of Texas Inequality Project.
} 
and the political economy approach.

\subsection{The income approach}

In classical economic theory, inequality of income was assumed to influence economic growth rates through savings and consumption. According to Adam Smith (1776), an increased division of labor raises productivity, but savings govern capital accumulation, which enables production growth. When the saving function is linear, e.g. $s_{i}=m y_{i}+b$, where $y_{i}$ is output per capita, $m$ is the marginal propensity to save, and $b$ is the per capita savings at zero income, aggregate saving behavior in an economy is not affected by the distribution of income (Stiglitz 1969). However, if the saving function is nonlinear, aggregate savings become dependent on the distribution of income.

When the saving function is linear or concave, distribution of income and wealth converge toward equality (Stiglitz 1969). If the saving function is convex, i.e. the marginal propensity to save increases with income, ${ }^{2}$ uneqalitarian stationary distributions, or steady-state equilibriums, are Pareto superior to egalitarian stationary distributions (appendix A). This is because, in the case of a convex saving function, more unequal distribution of income results in higher capital intensity through greater aggregate savings. In these unegalitarian steady-state equilibria, income and consumption for all individuals are greater than in egalitarian steady-state equilibria. In addition, in a steady-state equilibrium, where income are distributed unevenly, the wealth of a nation is greater than in the steady-state equilibriuim, where incomes are distributed evenly. However, these steady-state equilibria exist only when all individuals have positive wealth. Thus, result may not apply, for example, to developing countries.

\footnotetext{
${ }^{2}$ The hypothesis of convex savings function is supported by empirical findings, see e.g. Dynan et al. (2004).
} 
As mentioned above, there is also a consumption "side" included in the classical income approach. Adam Smith (1776) argued that production growth is not possible without sufficient demand. According to Smith, sufficient demand in the economy would be achieved, when every man were able to "provide for himself and his family". This line of reasoning was developed further by Keynes (1936). According to Keynes, demand is the basis for investments and, because inequality lowers aggregate consumption, inequality of income will lead to slower economic growth. Although this demand, or Keynesian, side approach has been neglected for some time, it has staged a massive comeback in the wake of the current economic crisis. The current economic slowdown is caused by a combination of a massive drop in the global demand and a severe credit crunch, which, naturally, are feeding each other (Krugman 2008). Keynes's (1936) argument that inequality decreases consumption is valid, if the saving function is convex. In this case, aggregate demand diminishes when income become more unequally distributed.

\subsection{The credit-market imperfections and combined approach}

The income approach emphasizes the effect of income inequality on savings and on physical capital accumulation. Credit market imperfections approach considers the effect of income inequality on the accumulation of human capital.

Credit market imperfections affect growth rates by limiting the division of labor (Fishman \& Simhon 2002). When credit-market imperfections are present, people cannot borrow against future income. This will restrict households' access to education. In this case, the initial level of capital and income inequality will determine the level of specialization. When the intensity of capital in the economy is small, unequal income distribution will encourage capital owners to invest in specialization. This will lead to higher division of labour and raise the econ- 
omy to a higher steady-state growth path. However, when the level of capital in the economy is large, more equal distribution of income will lead to wide based demand for goods and to higher level of education and division of labour. In this case, equal income distribution will lead to faster steady-state growth.

Galor and Moav (2004) have combined the credit market and income approaches. In their model, the engine of economic growth changes from physical capital to physical and human capital in the process of economic development. The process of economic development is divided into two regimes, which have their own steady-state growth paths.

Economies in the first regime are underdeveloped, aggregate physical capital is small, and the rate of return to human capital is lower than the rate of return to physical capital (Galor \& Moav 2004). There are two types of individuals in the economy: those who own the physical capital (the rich) and those who do not (the poor). The poor consume their entire income (wages) and are not engaged in saving and on capital accumulation. Thus, there is a temporary steady-state equilibrium where the poor are in poverty trap and the rich get richer. Inequality increases aggregate savings by increasing the income of the rich and greater aggregate savings fuel physical capital accumulation. ${ }^{3}$

In the second regime, physical capital accumulation by the rich has increased the rate of return to human capital so high that it induces human capital accumulation (Galor \& Moav 2004). In this regime, both human and physical capital are engines for economic development. Since individuals' investment in human capital is subjected to diminishing marginal returns, the return to human capital investments is maximized when investment in human capital is widely spread among

\footnotetext{
${ }^{3}$ In modern less developed economies, it is possible that also human capital drives growth, if the capital and skill-biased technology is imported. In this case, the effect of inequality on growth would be mixed or negative (Galor \& Moav 2004).
} 
the population. Because access to credit is constrained, human capital investment is maximized when income in the economy are distributed evenly. However, in a certain phase of economic development income of every individual becomes so high that credit constraints become less binding. In this locally stable steady-state equilibrium, the effect of inequality on growth becomes less significant.

\subsection{The political economy approach}

Political economy models assume that preferences of individuals are aggregated through political process. Therefore, redistribution of incomes and economic growth are driven by the political process. Political process can be driven by a median voter or by organized social groups.

In the model by Perotti (1993), credit-markets are imperfect and median voter defines the redistribution of incomes through taxation and the level of subsidies to all income classes. In the first period, individual can invest in education, which increases the income of an individual in the second period and has a positive externality on the second period productivity of other individuals. Individuals can also choose not to invest in education in the first period. In the first period, individuals vote over the level of income taxes, and the revenues of these taxes are redistributed as per capita subsidy, which is constant over all individuals. The utility of individual $i$ depends on the tax rate in period 1 and on the amount of other individuals that have invested in education in period 1. The tax rate determines the possibility of agent $i$ to invest in education in period 1. If the tax rate is too high, individual $i$ cannot invest in education because credit-markets are imperfect. However, higher tax rate and higher per capita subsidies makes it possible for many other individuals to invest in education, which increases the pre-tax income of individual $i$ in the second period. 
Now the steady-state equilibrium reached by the economy depends on the initial distribution of income (Perotti 1993). If the aggregate capital in the economy is very small, redistribution of income through taxes and subsidies will result in a poverty trap where no one is able to acquire education. In this case, more unequal distribution of income will help the economy because in that case at least some individuals can acquire education and increase the level of human capital in the economy. As economy becomes more developed, very unequal income distribution may diminish growth because the accumulation of more human capital would require that middle-income and poor individuals acquire education, as the rich have already educated themselves. In an rich economy, only the poor may increase the level of human capital in the economy and higher steady-state growth path requires that income are distributed evenly.

\section{Time series analysis of panel data}

The theoretical models presented above predict steady-state equilibrium relations, or stationary distributions, that may exist between income inequality and the evolution of output. The estimation of these theoretical stationary distributions requires that we know the time series features of the variables in the model. First, the stationarity of the data must be tested. If variables are found to be integrated processes of order 1, the existence of equilibrium relations can be tested by testing for cointegration. If cointegrating relations are found, the cointegrating vector can be estimated using estimators developed for panel cointegrated data. Many models also assume that income distribution and economic development are determined endogenously, which has to be taken into account in the estimation. 


\subsection{Data}

Data for this study consist at four variables: real GDP per capita, EHII2.1 Gini index, portion of investments on GDP, and average years of schooling. Gross domestic product is stated in real terms with the base year of 1996. Investments are gross investments as a portion of GDP. The data on GDP and investments are from Penn World Tables (Heston et al. 2006). The EHII2.1 Gini index is from the University of Texas Inequality Project (Galbraith \& Kum 2006) and average years of shooling is from Barro and Lee's (2000) dataset.

Many of the previous studies made on the relationship between income inequality and economic growth have used the Deininger and Squire's (1996) Gini index as a measure on income distribution. ${ }^{4}$ The main reason why so many researchers have relied on the Deininger and Squire's Gini index has been its alleged "high quality". However, as pointed out by Atkinson and Brandolini (2001, p. 780), Deininger and Squire's dataset includes so many different datasets that in many cases it would be "highly misleading to regard Deininger and Squire's "high quality" estimates as a continuos series". The different country-related datasets in Deininger and Squire's "high quality" dataset may also not be comparable with each other. These are serious problems for estimation, because the statiscal inference requires that observations are from the same parent population. If the observations are not comparable, there is no one coherent parent population and the parameter estimates may be spurious.

Many scholars studying income inequality have already switched to Gini index provided by UNU-Wider. ${ }^{5}$ Although UNU-Wider Gini index seems more consistent and accurate than Deininger and Squire's Gini index, they share one

\footnotetext{
${ }^{4}$ These include Barro (2000), Banerjee and Duflo (2003), Forbes (2000), and Chen (2003).

${ }^{5}$ World Institute for Development Economics Research of the United Nations University
} 
deficiency. Both Gini indexes are unevenly distributed through time, which restricts their use in time series analysis. However, Galbraith and Kum (2006) have gathered a EHII2.1 Gini index, which has a consistent, long time series for several countries.

According to Galbraith and Kum (2006), EHII2.1 Gini index has three clear advantages over the Deininger and Squire's Gini index. It has more than 3000 estimates, while Deininger and Squire have only about 700 "high quality" estimates. EHII2.1 gets its accuracy from the Industrial data published annually by the United Nations Industrial Development Organization (UNIDO). This way changes over time and differences across countries in pay dispersion are reflected in income inequality. All estimates are also adjusted to household gross income, which makes them congruent. Values of the EHII2.1 also correspond to the estimates of income distributions of other research institutes, such as the OECD, better than those of Deininger and Squire's Gini index (Föster \& Pearson 2002, Galbraith \& Kum 2004).

\subsection{Panel unit root tests}

There are 60 countries in the EHII2.1 data set where the time series of Gini index is consistent and at least 20 years long. After individual unit root tests, 7 countries were discarded from the set because their series of Gini index or GDP did not seem to follow a $I(1)$ process according to the ADF-test. ${ }^{6}$ Descriptive statistics of the remaining 53 countries are presented in table 1 and a list of the 53 countries is presented in appendix B.

\footnotetext{
${ }^{6}$ This is a precautionary method. Karlsson and Löthgren (2000) have studied how few stationary series in the panel can alter the results of panel unit root tests. They found that when the time dimension of a dataset is large (50 or over), small fraction of stationary series in the dataset results to high power and vice versa. Therefore, there is a risk that panels with large $T$ would erroneously be modeled as stationary and panels with small $T$ as non-stationary.
} 
Table 1: Descriptive statistics

\begin{tabular}{lcccc}
\hline \hline variable & mean & std. deviation & min. & max. \\
\hline GDP & 6624.25 & 6740.03 & 145.24 & 43138.33 \\
GDP growth (\%) & 2.533 & 4.860 & -26.774 & 56.074 \\
Gini index & 39.571 & 6.631 & 23.074 & 58.975 \\
investments (\%) & 18.112 & 8.525 & 0.191 & 52.531 \\
average schooling (\%) & 4.602 & 2.773 & 0.390 & 10.090 \\
\hline
\end{tabular}

Most of the time series analysis methods for panel data assume that there is no cross-unit correlation present in the panel. When dealing with economic variables, this restriction is quite uncomfortable, because for example business cycles do transfer to neighboring countries quite easily in modern open economies. To account for the obvious cross-sectional correlation present in the data, the results of Pesaran's (2007) panel unit root test allowing for cross-sectional dependence are also reported.

The traditional panel unit root tests used in this study are based on the following regression:

$$
\Delta y_{i t}=\rho_{i} y_{i, t-1}+\delta_{i}+\eta_{i} t+\theta_{t}+\epsilon_{i t}
$$

where $\delta_{i}$ are the individual constants, $\eta_{i} t$ are the individual time trends, and $\theta_{t}$ is the common time effect. All tests rely on the assumption that $E\left[\epsilon_{i t} \epsilon_{j s}\right]=0 \forall t, s$ and $i \neq j$, which is required for the calculation of common time effects. The null hypothesis in all tests is $H_{0}: \rho_{i}=0 \forall i$, but the tests have different assumptions about the heterogeneity of $\rho$ and on the alternative hypothesis. ${ }^{7}$ The inclusion of individual constants and time trends is also optional.

Pesaran's (2007) test is based on a regression

$$
\Delta y_{i t}=\rho y_{i, t-1}+\eta_{i} t+\alpha_{i}+\delta_{i} \theta_{t}+\epsilon_{i t},
$$

\footnotetext{
${ }^{7}$ For example, Im et al. (2003) test's alternative hypothesis is that some but not all of the individual series may have unit roots vs. Levin et al. (2002) test which assumes homogeneity between cross-sections.
} 
where $\alpha_{i} \mathrm{~s}$ are the individual constants, $\eta_{i} t$ are the individual time trends, $\theta_{t}$ is the common time effect, whose coefficients, $\delta_{i}$, are assumed to be non-stochastic and they measure the impact of the common time effect on series $i, \epsilon_{i t} \sim$ i.i.d.N $\left(0, \sigma^{2}\right)$ over $t$, and $\epsilon_{i t}$ is independent of $\epsilon_{j s}$ and $\theta_{s}$ for all $i \neq j$ and $s, t$. Cross-sectional dependence is allowed through the common time effects which are proxied by the cross-section mean of $y_{i t}\left(\bar{y}_{t}=N^{-} 1 \Sigma_{j=1}^{n} y_{j t}\right)$ and its lagged values, $\bar{y}_{t-1}, \bar{y}_{t-2}$, etc. The null hypothesis is that $H_{0}: \rho_{i}=0 \forall i$ and alternative hypothesis allows for some of the tested series to be nonstationary.

Two different types of panel unit root tests are used. Levin, Lin and Chu's (2002) (LLC) test assume a common unit root process, i.e. $\rho_{i}=\rho \forall i$. Im, Pesaran, and Shin's (2003) test (IPS), Fisher type ADF and PP tests, presented by Maddala and Wu (1999), and Pesaran's (2007) test allow for a individual unit root processes.

Summary of the results of the five panel unit root tests are presented in table 2. ${ }^{8}$ Individual trends and constants are included in the tests for the GDP and Gini index. For the GDP it is natural to allow for both individual time trends and constants, because the time series of the GDP usually follows a clear upward trend. The time series of Gini index also seems to be trending in many countries, ${ }^{9}$ and so it is also allowed to have individual time trends. GDP growth and investments seem not to exhibit a trend, and so only individual constants are included in their tests. ${ }^{10}$ All other tests use the unbalanced panel data of 53 countries, ${ }^{11}$ except

\footnotetext{
${ }^{8}$ All the test were performed with Eviews 6, except Pesaran's (2007) test which was done with Stata. Lag lengths have been determined using Schwarts information criterion, spectral estimation has been conducted with Bartlett kernel and bandwidth has been selected using Newey-West method.

${ }^{9}$ The time series were inspected visually.

${ }^{10}$ If individual trends are included, the results change only marginally and both series are still stationary according to all five tests.

${ }^{11}$ Panel unit root test were also conducted using the whole dataset of 60 countries. Results were similar to those presented in table 2.
} 
Pesaran's (2007) test where a balanced panel of 38 countries with 25 yearly observations is used. ${ }^{12}$

Table 2: Panel unit root tests

\begin{tabular}{lccccc}
\hline \hline variable & LLC & IPS & ADF & PP & Pesaran* \\
\hline $\log ($ GDP $)$ & 9.068 & 15.092 & 15.855 & 16.072 & 0.709 \\
& $(1.0000)$ & $(1.0000)$ & $(1.0000)$ & $(1.0000)$ & $(0.761)$ \\
GDP growth & -45.913 & -25.415 & 572.04 & 599.36 & -12.089 \\
& $(<.0001)$ & $(<0.0001)$ & $(<.0001)$ & $(<.0001)$ & $(<.0001)$ \\
$\log$ (Gini index $)$ & 0.549 & 2.702 & 77.387 & 70.521 & -0.790 \\
& $(0.7085)$ & $(0.9966)$ & $(0.9834)$ & $(0.9968)$ & $(0.215)$ \\
$\log$ (investments) & -6.071 & -7.558 & 244.13 & 212.80 & -4.529 \\
& $(<.0001)$ & $(<.0001)$ & $(<.0001)$ & $(<.0001)$ & $(<.0001)$ \\
\hline
\end{tabular}

The $p$-values of the test statistics are presented in parentheses. All tests include individual effects and trends except the test for GDP growth and investments which include only individual effects. Lag lengths were determined using Schwarts information criterion. All other tests use unbalanced panel of 53 countries except Pesaran's test, where the panel is balanced including 38 countries and 25 yearly observations.

According to all five tests, the logarithmic GDP and Gini index seem to follow a $I(1)$ process, and the series of GDP growth and investments seem to be stationary. ${ }^{13}$ However, as mentioned above, it is likely that at least some of the tested series are cross-sectionally correlated or cointegrated. This would violate the assumption of uncorrelated residuals among cross-sections, i.e. $E\left[\epsilon_{i t} \epsilon_{j s}\right] \neq 0$ $\forall t, s$ and $i \neq j$. Banerjee et al. (2005) have studied the effect of the violation of the assumption of no cross-unit cointegration on rejection frequencies of the null hypothesis. Their results show that in the presence of cross-unit cointegration, the ADF, PP, and IPS tests grossly overreject the null hypothesis of unit root with small time $(T)$ and relatively large cross-sectional $(n)$ dimensions of data. Here, all these tests accept the null hypothesis in the series of the Gini index and GDP.

\footnotetext{
${ }^{12}$ Pesaran's (2007) test requires that the panel is balanced.

${ }^{13}$ Results were the same when original data of 60 countries are used.
} 
As Pesaran's (2007) test also accepts the null hypothesis for the Gini index and GDP, they seem very likely to be unit root processes. ${ }^{14}$ As Pesaran's test finds the GDP per capita growth and investments to be stationary, they can be assumed to be stationary.

\subsection{Panel cointegration test}

The possible cointegration between Gini index and GDP is tested with Pedroni's (2004) panel cointegration test which consist of 11 different test statistics. ${ }^{15} \mathrm{Pe}$ droni's panel cointegration test is based on the model:

$$
y_{i t}=\alpha_{i}+\delta_{i} t+\beta_{i} X_{i t}+\epsilon_{i t},
$$

where $\alpha_{i}: \mathrm{s}$ and $\delta_{i}: \mathrm{s}$ allow for member specific fixed effects and deterministic trends, $X_{i t}$ is a $m$-dimensional column vector of explanatory variables for each member $i$, and $\beta_{i}$ is an $m$-dimensional row vector for each member $i$. The variables $y_{i t}$ and $X_{i t}$ are assumed to be integrated of order one. Thus, under the null of no cointegration, the residual $e_{i t}$ will also be $I(1)$. Pedroni's test is based on running the auxiliary regression on every cross-section

$$
\epsilon_{i t}=\rho_{i} \epsilon_{i t}+u_{i t},
$$

where $E\left[u_{i t} u_{j s}\right]=0 \forall s, t, i \neq j$. There are two null hypotheses: $\rho_{i}=\rho<1 \forall i$ (within- dimension test) and $\rho_{i}<1 \forall i$ (between-dimension test).

The model for testing for cointegration between the Gini index and GDP is:

$$
\log \left(G D P_{i t}\right)=\alpha_{i}+\delta_{i} t+\gamma_{i} \log \left(\text { Gini }_{i t}\right)+\beta_{i} \log (\text { investments })+\epsilon_{i t},
$$

\footnotetext{
${ }^{14}$ First differenced series are stationary according to all panel unit root tests. The GDP and Gini index thus seem to be $I(1)$.

${ }^{15}$ There are 7 different test statistics, but Eviews 6 gives also the results of weighted test statistics on the first four tests. Tests statistics include the panel versions of $P P$ and $A D F$ tests, a form of the average of the Phillips and Ouliaris (1990) test statistics $(\rho)$, and panel variance ratio statistics $(v)$.
} 
where the changes in GDP are explained by the changes in the Gini index and on the level of investments, and $\left(1,-\gamma_{i}\right)$ is the individual cointegration vector between Gini index and GDP. Results of Pedroni's panel cointegration tests on equation (5) are presented in table $3 .{ }^{16}$

Table 3: Pedroni's panel cointegration test statistics for $\log (\mathrm{GDP})$ and $\log ($ Gini index)

\begin{tabular}{lcccc}
\hline \hline Within-dimension & & & & \\
& statistic & prob. & weight. statistic & prob. \\
panel $v$-statistic & 49.309 & $<.0001$ & 44.793 & $<.0001$ \\
panel $\rho$-statistic & 7.152 & $<.0001$ & 7.329 & $<.0001$ \\
panel PP-statistic & 2.888 & 0.0062 & 3.494 & 0.0009 \\
panel ADF-statistic & 2.489 & 0.0180 & 3.039 & 0.0039
\end{tabular}

Between-dimension

statistic prob.

group $\rho$-statistic $\quad 9.417<.0001$

group PP-statistic $\quad 4.555<.0001$

group ADF-statistic $\quad 2.313 \quad 0.0275$

countries 53

observations 1961

Within-dimension tests presuppose common AR coefficients among cross sections. Betweendimension presupposes individual AR coefficients. Lag length were determined with Schwarz information criterion. Spectral estimation was done with Bartlett method and bandwidth was selected with Newey-West method.

According to all of the 11 test statistics presented in table 3, the series of Gini and GDP are cointegrated at the 5\% level. The test is also conducted using only the Gini index as an explanatory variable for GDP. In this case, 9 of the 11 test statistics find the GDP and Gini index to be cointegrated. If the test is conducted using only investments as an explanatory variable, all of the 11 test statistics find the investments and GDP to be cointegrated. This indicates that there might be cross-sectional cointegration relations in the panel. Cross-unit cointegration can

\footnotetext{
${ }^{16}$ The test was performed with Eviews 6 .
} 
bias the results of panel unit root tests towards type I error, i.e. that hypothesis of unit root is rejected far too often (Banerjee et al. 2005, Breitung \& Pesaran 2005). Even if this would no be the case, the results of Pedroni's (2004) test leave only little room for a doubt. If investments would be a stationary process, there could not be a linear combination between GDP and investments that would be stationary. ${ }^{17}$ Thus, investments is assumed to be a $I(1)$ process that is cointegrated with GDP.

As with panel unit root tests, the presence of cross-sectional cointegration may have affected the results. However, according to Banerjee et. al. (2004), panel $v$ and panel $\rho$-statistics keep their nominal size reasonably well in the presence of cross-sectional cointegration even with small $T$ and relatively large $n$ dimensions of data. Because all these test statistics reject the hypothesis of no cointegration, GDP and Gini index and GDP and investments seem very likely to be cointegrated. ${ }^{18}$

\section{Estimation}

To compare the results of different estimation methods, two different estimation frameworks are used. First, in section 4.1 averaged GDP per capita growth rates are regressed on explanatory variables in cross-sectional setting. Second, in section 4.2 GDP per capita levels are regressed on explanatory variables in panel setting to find out the cointegrating coefficient of Gini index.

\footnotetext{
${ }^{17}$ Assuming that GDP per capita is a $I(1)$ process.

${ }^{18}$ The cointegration between $\log$ (GDP) and $\log$ (Gini index) and $\log$ (GDP) and $\log$ (investments) were also tested with Johansen's combined Fisher panel cointegration test developed by Maddala and Wu (1999). According to it, both GDP and Gini index and GDP and investments are cointegrated of order one. Detailed results are available upon request.
} 


\subsection{Estimation using average growth rates}

In growth regressions, the growth rate has usually been averaged over 5 years or more to eliminate the possible business cycles. Five year business cycle "smoothing" is usually appropriate, because it is short enough to capture the possible structural changes appearing in the relation. Five year intervals mean that the estimated coefficients represent short or medium term effects. The estimation of long run growth elasticities would require averages of 20 years or more.

Here, average growth rates of 30 years are used. The risks related to the use of multidecade averages in estimation are clear. When the dependent variable is averaged over a long period of time, it loses a lot of information and the risk for spurious regressions is high, because there is no control over the possible changes in the relation between dependent and explanatory variable(s). It is also problematic for statistical inference to assume that the changes in some variable in one year would affect some other variable for the next 20 years or more.

The model to be estimated is a Barro-type extended version of the neoclassical growth model:

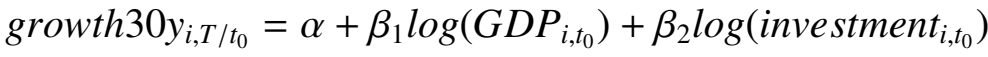

$$
\begin{aligned}
& +\beta_{3} \log \left(\text { Gini }_{i, t_{0}}\right)+\beta_{4} \log \left(\text { average schooling }_{i, t_{0}}\right)+\epsilon_{i},
\end{aligned}
$$

where the 30 year average GDP per capita growth rates are regressed against the values of explanatory variables at the beginning of the averaging. All the countries whose 30 year average growth rate was negative, are discarded from the estimation. If a country has experienced a deceleration in the GDP in the 30 year period, it is highly likely that this has resulted from some structural factors rather than changes in the explanatory variables included in equation (6). Results of estimation of equation (6) are presented in table 4.

According to the results, none of the parameter estimates is statistically sig- 
Table 4: Regression results using average growth rates between 1970-1999

\begin{tabular}{lccc}
\hline \hline Dependent var.: & Growth 30y & Growth 30y & Growth 30y \\
\hline Constant & $6.1963^{* *}$ & 9.227 & 9.1026 \\
& $(2.2600)$ & $(6.7071)$ & $(7.1256)$ \\
$\log (G D P)_{70}$ & -0.3209 & -0.5514 & -0.7331 \\
& $(0.3526)$ & $(0.5656)$ & $(0.5992)$ \\
$\log (\text { investments })_{70}$ & 0.0455 & 0.0480 & 0.0561 \\
& $(0.0291)$ & $(0.0298)$ & $(0.0324)$ \\
$\log (\text { Gini })_{70}$ & - & -0.0345 & -0.0125 \\
& & $(0.0777)$ & $(0.1058)$ \\
$\log (\text { averageschooling })_{70}$ & - & - & 0.0862 \\
& & & $(0.2743)$ \\
\hline estimator & OLS & OLS & OLS \\
countries & 46 & 46 & 46 \\
\hline
\end{tabular}

The estimated period is 1970-1999. Explanatory variables are measured in 1970. Standard errors are presented in parentheses. All estimations are done using White heteroskedasticity-consistent standard errors and covariances.

nificant at the $5 \%$ level. Thus, the results of table 4 show that estimation using multi-decade growth averages leads to high standard errors of parameter estimators, which in turn leads to economically uncongenial results (e.g. investments have no statistically significant effect on GDP growth).

However, there is also an obvious econometric problem present in standard growth regression models, when they are applied to long-run growth relationships. To see this, consider a standard growth regression in panel setting:

$$
\triangle G D P_{i t}=\rho\left(G D P_{i, t-1}\right)+\beta\left(G i n i_{i, t-1}\right)+\epsilon_{i t} .
$$

Now, if GDP and Gini index are $I(1)$ processes, $\rho \rightarrow 0$, and $\beta \rightarrow 0$, because integrated processes cannot provide any relevant information on stationary process. Thus, standard growth regressions would produce nonsense estimates on the long-run effect on inequality to growth. ${ }^{19}$

\footnotetext{
${ }^{19}$ The same result, naturally, applies to time series estimation.
} 


\subsection{Estimation of the cointegrating coefficient of Gini index}

\subsubsection{Estimation and inference in cointegrated panels}

Conventional limit theorems assume one index ( $n$ or $T$ ) to pass to infinity. The limit theory for panels with large cross-sectional $(n)$ and time $(T)$ dimensions needs to allow both indexes to pass to infinity. This has some profound effects for estimators. For example the OLS estimator is not asymptotically unbiased, and the standard GMM estimator is inconsistent for panel cointegrated data (Kao \& Chiang 2000).

Several estimators for cointegrated panel data have been proposed. Probably the most commonly used estimators have been the fully-modified OLS (FMOLS) proposed by Phillips and Moon (1999) and Pedroni (2000), and the dynamic OLS (DOLS) proposed by Kao and Chiang (2000). The major problem for estimators in cointegrated panel data has been the modeling of simultaneous cross-sectional and time series dependence (Phillips \& Moon 1999). Mark and Sul (2003) have developed a version of DOLS estimator that allows for simultaneous cross-sectional and time series dependence.

Mark and Sul (2003) consider a DOLS estimator with fixed effects, fixed effects and heterogenous trends, and with fixed effects, heterogenous trends, and common time effects. The last model accounts for cross-sectional dependence by introducing a common time effect. Mark and Sul's model assumes that observations on each individual $i$ obey the following triangular representation

$$
y_{i t}=\alpha_{i}+\lambda_{i} t+\theta_{t}+\gamma^{\prime} x_{i t}+u_{i t}
$$

where $\left(1,-\gamma^{\prime}\right)$ is a cointegrating vector between $y_{i t}$ and $x_{i t}$, which is identical across individuals, $\alpha_{i}$ is a individual-specific effect, $\lambda_{i} t$ is a individual-specific linear trend, $\theta_{t}$ is a common time-specific factor, and $u_{i t}$ is a idionsyncratic error 
that is independent across $i$, but possibly dependent across $t$. Model (8) allows for a limited form of cross-sectional correlation, where the equilibrium error for each individual is driven in part by $\theta_{t}$.

Panel DOLS eliminates the possible endogeneity between explanatory variables and the dependent variable by assuming that $u_{i t}$ is correlated at most with $p_{i}$ leads and lags of $\Delta x_{i t}$ (Mark \& Sul 2003). The possible endogeneity can be controlled by projecting $u_{i t}$ onto these $p_{i}$ leads and lags:

$$
u_{i t}=\sum_{s=-p_{i}}^{p_{i}} \delta_{i, s}^{\prime} \Delta x_{i, t-s}+u_{i t} *=\delta_{i}^{\prime} z_{i t}+u_{i t}^{*}
$$

The projection error $u_{i t}^{*}$ is orthogonal to all leads and lags of $\Delta x_{i t}$ and the estimated equation becomes

$$
y_{i t}=\alpha_{i}+\lambda_{i t}+\theta_{t}+\gamma^{\prime} x_{i t}+\delta_{i}^{\prime} z_{i t}+u_{i t}^{*}
$$

where $\delta_{i}^{\prime} z_{i t}$ is a vector of projection dimensions. The consistent estimation of (10) is based on sequential limits, i.e. as $T \rightarrow \infty$ then $n \rightarrow \infty$. Equation (10) can be feasible estimated in panels with small to moderate $n$.

Wagner and Hlouskova (2007) have compared the performance of different types of estimators for panel cointegrated data. They found that Mark and Sul's (2003) DOLS system estimator (panel DOLS) performs best in the case of crossunit correlation or cointegration compared to several other estimators developed for panel cointegrated data. ${ }^{20}$

It is, of course, possible that the common time-effect included in panel DOLS estimation cannot capture all the cross-sectional correlation present in the data. This is a problem especially if there remains correlation between equilibrium error, $u_{i t}$, and leads and lags of other cross-sections $\Delta x_{j t}, j \neq i$. In this case the

\footnotetext{
${ }^{20}$ The tested estimators included FM-OLS presented by Phillips and Moon (1999), DOLS presented by Kao and Chiang (2000) and Mark and Sul (2003), one-step VAR, and two-step VAR presented by Breitung (2005)
} 
panel DOLS exhibits the same form of second order asymptotic bias as pooled OLS (Mark \& Sul 2003).

To correct for this, Mark et al. (2005) have developed a panel dynamic seemingly unrelated regression estimator that controls for the possible endogeneity between equilibrium errors and cross-equations and that is efficient when errors are correlated across cross-sectional units. Panel DSUR estimator can be used when the cross-section is small relative to time series.

The data generation process in Mark et al. (2005) DSUR estimator is of the form

$$
\begin{aligned}
& y_{i t}=\beta_{i} x_{i t}^{\prime}+u_{i t}, \\
& \triangle x_{i t}=e_{i t}
\end{aligned}
$$

where there are $n$ cointegrating regression each with $T$ observations, and $x_{i t}$ and $e_{i t}$ are $k \times 1$ dimensional vectors. Endogeneity is controlled for by including leads and lags of (12) into the regression, as in panel DOLS estimator presented above. Panel DSUR estimates a long-run covariance matrix that is used in estimation of equation (11). This makes panel DSUR more efficient than panel DOLS when cross-sections are dependent. The efficiency of panel DSUR actually improves as the correlation between cross-sections increases.

\subsubsection{Estimation results}

The estimated model now includes a measure of physical capital accumulation (investments) and a measure of income inequality (Gini index). ${ }^{21}$ Panel DOLS estimation is used to estimate the following equation:

$$
\log \left(G D P_{i t}\right)=\alpha_{i}+\gamma_{1}^{\prime} \log \left(\text { investment }_{i t}\right)+\gamma_{2}^{\prime} \log \left(\text { Gini }_{i t}\right)+\lambda_{i} t+\theta_{t}+u_{i t},
$$

\footnotetext{
${ }^{21}$ The data on average schooling cannot be included in estimation, because Barro \& Lee's (2000) dataset uses intervals of five years.
} 
where $\alpha_{i}$ are individual constant, $\lambda_{i} t$ are individual trends, $\theta_{t}$ is common time effect, $\left(1,-\gamma_{1}^{\prime},-\gamma_{2}^{\prime}\right)$ is a cointegrating vector between GDP, investments and Gini index, and $u_{i t}$ is a idiosyncratic error. Table 5 presents the results of fixed effects DOLS estimation of equation (13). ${ }^{22}$

Table 5: DOLS estimates of the cointegrating coefficient of Gini index

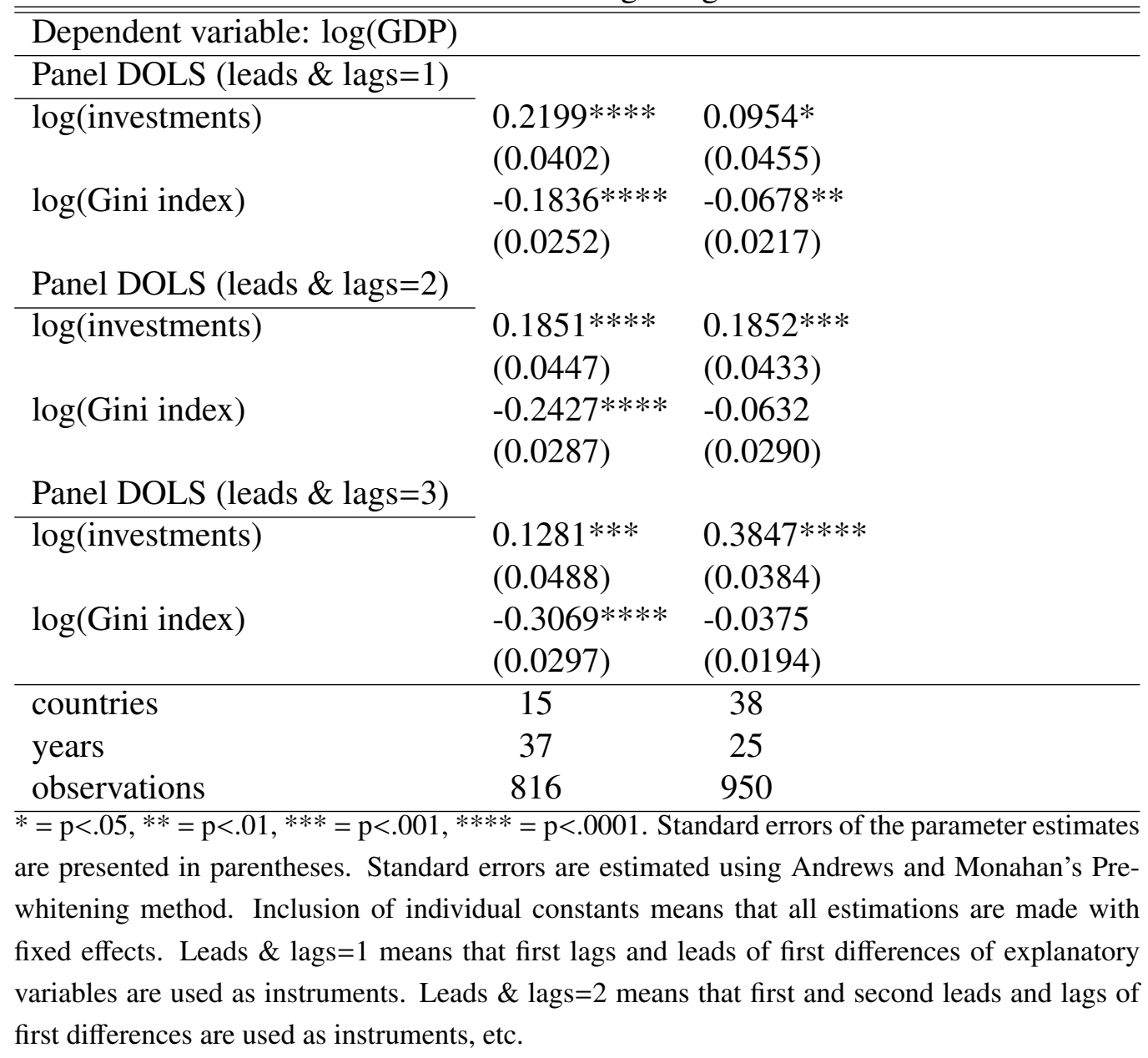

The cointegrating coefficient of investments is positive and statistically significant in all estimation. The cointegrating coefficient of Gini index is negative and statistically significant at the 5\% level in all estimations using the dataset with 37

\footnotetext{
${ }^{22}$ Estimation was conducted with Gauss. The program code was provided by Mark and Sul (2003).
} 
yearly observations. In estimations using the dataset with 25 yearly observations, the cointegrating coefficient of the Gini index is not statistically significant at the $5 \%$ level when two and three leads and lags of the first differences are used as instruments for the explanatory variables.

Thus, the results of panel DOLS estimation using the 15 country dataset with longer time dimension imply that the long-run growth elasticity with respect to income inequality would be negative. However, the results of panel DOLS estimation using the 38 country dataset with shorter time dimension are inconclusive.

\subsection{Estimation of group-related elasticities of growth}

Recently, Hineline (2007) has found that the estimated coefficient of explanatory variables generally used in growth regressions differ substantially between OECD and non-OECD countries. Pedroni's (2004) panel cointegration test also allowed for individual cointegrating coefficients between statistical units. It is therefore possible that the cointegrating coefficient of Gini index may differ in different groups of countries. To test for the homogeneity of cointegrating coefficient of Gini index, countries are divided into OECD member and non-OECD countries according to their year of initiation. In other words, group "OECD" includes those countries that became members of the OECD before or in 1972 .

The results obtained using the OECD and non-OECD country data sets are contradictory and inconclusive. For example, the estimate of the cointegrating coefficient of Gini index differs across groups and estimators. ${ }^{23}$ This implies that there are such differences in the relation between inequality and growth even within the OECD countries that it is more informative to group the countries according to some other variable.

\footnotetext{
${ }^{23}$ The detailed results are available upon request.
} 
One obvious grouping variable is the level of economic development, especially as many of the theories presented in section 2 predict that the effect of inequality on growth may differ in different stages of economic development. To estimate the long-run growth elasticities of income inequality and physical capital accumulation in different income groups countries in the dataset are divided into three income groups. To make the estimation of income groups asymptotically feasible, i.e. to make the groups large enough, countries are divided into three equally sized groups. This is done using all the countries in the 53 country dataset that have observations on the GDP in 1972. There are 48 such countries in the dataset of 53 countries and so we have 3 groups of 16 countries. The thresholds for these groups become: GDP per capita of \$1270 in 1972 for less developed countries, GDP per capita between $\$ 1271$ and \$3715 in 1972 for middle-income countries, and GDP per capita above \$3716 in 1972 for rich countries. Table 10 presents the results of panel DOLS estimation of equation (13) in different income groups of countries. ${ }^{24}$

The cointegrating coefficient of investments is positive and statistically significant in less developed economies, but not statistically significant in middleincome and rich economies when two or three leads and lags are used as instruments. The cointegrating coefficient of Gini index is negative and statistically significant at the 5\% level in middle-income and rich economies. In less developed economies, the cointegrating coefficient of Gini index is positive and statistically significant at the 5\% level when two and three leads and lags are used as instruments.

The results of table 6 have two implications. The elasticity of growth with respect to investments, i.e. physical capital accumulation, diminishes in accor-

\footnotetext{
${ }^{24}$ Estimation was conducted with Gauss. The program code was provided by Mark and Sul (2003).
} 
Table 6: DOLS estimates of the cointegrating coefficients of Gini index in different income groups

\begin{tabular}{|c|c|c|c|}
\hline \multicolumn{4}{|l|}{ Dependent variable: $\log ($ GDP $)$} \\
\hline & less-developed & middle-income & rich \\
\hline \multicolumn{4}{|l|}{ Panel DOLS (leads \& lags=1) } \\
\hline \multirow[t]{2}{*}{$\log$ (investments) } & $0.1766 * * * *$ & $0.1000 *$ & -0.0018 \\
\hline & $(0.0366)$ & $(0.0496)$ & $(0.0974)$ \\
\hline \multirow[t]{2}{*}{$\log ($ Gini index $)$} & -0.0069 & $-0.1317^{*}$ & $-0.1443^{*}$ \\
\hline & $(0.0190)$ & $(0.0559)$ & $(0.0627)$ \\
\hline \multicolumn{4}{|l|}{ Panel DOLS (leads \& lags=2) } \\
\hline \multirow[t]{2}{*}{$\log ($ investments $)$} & $0.2678 * * * *$ & 0.0803 & 0.0919 \\
\hline & $(0.0583)$ & $(0.0543)$ & $(0.0742)$ \\
\hline \multirow[t]{2}{*}{$\log ($ Gini index $)$} & $0.0549 *$ & $-0.1520 * * * *$ & $-0.2417 * * * *$ \\
\hline & $(0.0238)$ & $(0.0299)$ & $(0.0490)$ \\
\hline \multicolumn{4}{|l|}{ Panel DOLS (leads \& lags=3) } \\
\hline \multirow[t]{2}{*}{ log(investments) } & $0.4492 * * * *$ & $0.2667 * * * *$ & $0.1962 * *$ \\
\hline & $(0.0366)$ & $(0.0397)$ & $(0.0596)$ \\
\hline \multirow[t]{2}{*}{$\log ($ Gini index $)$} & $0.1014 * * * *$ & $-0.2175 * * * *$ & $-0.4558 * * * *$ \\
\hline & $(0.0152)$ & $(0.0397)$ & $(0.0424)$ \\
\hline countries & 11 & 12 & 15 \\
\hline years & 25 & 25 & 25 \\
\hline observations & 275 & 300 & 375 \\
\hline
\end{tabular}

dance with the level of economic development and the elasticity of growth with respect to income inequality changes in the process of economic development. In early stages of economic development, the effect of income inequality on growth is positive, but turns negative as the economy becomes more developed. The negative growth elasticity of inequality also increases in accordance with the level of economic development.

However, as mentioned above, panel DOLS may be asymptotically biased if there remains correlation between equilibrium error, $u_{i t}$, and leads and lags of other cross-sections $\Delta x_{j t}, j \neq i$. To account for the possible cross-equation corre- 
lation, the panel DSUR estimator is applied to income group estimation. Because panel DSUR requires that the time series dimension is clearly larger than crosssectional dimension, a dataset that has 34 yearly observations on 24 countries is used. Grouping of countries is done in the same way as presented above. There are 44 countries in the dataset of 53 countries that have observations on real GDP per capita in 1963 . Thus, 33\% of all countries would give 14.6 countries per group. Because of this, 14 countries are included in the groups of less developed and rich countries and 16 countries to the group of middle-income countries. The thresholds for these groups become: GDP per capita under \$637 in 1963 for less developed economies, GDP per capita between \$638 and \$1903 in 1963 for middle-income economies, and GDP per capita over \$1904 in 1963 for rich economies. Table 7 gives the results of panel dynamic SUR estimation of equation (13) in different income groups. ${ }^{25}$

According to the results presented in table 7, the cointegrating coefficient of investments is positive and statistically significant at the 5\% level in less developed and middle-income countries. ${ }^{26}$ The cointegrating coefficient of investments is not statistically significant at the 5\% level in any of the estimations of rich countries. The elasticity of growth with respect to investments also gets smaller as countries get richer. This implies that the influence of investments on per capita growth diminishes as the level of physical capital increases. However, it is unexpected that the cointegrating coefficient of investments is not positive and statistically significant in rich economies. The cointegrating coefficient of the Gini index is negative and statistically significant at the $5 \%$ level in all income groups. ${ }^{27}$

\footnotetext{
${ }^{25}$ Estimation was conducted with Gauss. The program code was provided by Mark et al. (2005).

${ }^{26}$ Estimations were also done with three leads and lags, but as there were no major changes in the results, only results of estimations with one and two leads and lags are presented here.

${ }^{27}$ Equation (13) was also estimated using only the data on 6 of the most developed countries. Results were similar to those presented in table 7.
} 
As such, results presented in table 7 contradict the results of panel DOLS estimation, where the cointegrating coefficient of the Gini index was positive and statistically significant in less developed economies when two and three leads and lags were used as instruments. This could result from cross-sectional correlation not captured by the common time effect, from correlation between equilibrium error and cross-equations, or from efficiency of panel DSUR compared to panel DOLS. To test this, four countries that were not present in the dataset of seven less-developed countries used in panel DSUR estimation are removed from the dataset of 11 countries used in panel DOLS estimation. The remaining seven country dataset is then estimated with panel DSUR and DOLS. The cointegrating coefficient of the Gini index is positive and not statistically significant in panel DOLS estimation, but turns to negative and statistically significant when panel

Table 7: DSUR estimates of the cointegrating coefficients of Gini index in different income groups

\begin{tabular}{|c|c|c|c|}
\hline \multicolumn{4}{|l|}{ Dependent variable: $\log (\mathrm{GDP})$} \\
\hline & less developed & middle-income & rich \\
\hline \multicolumn{4}{|l|}{ Panel DSUR (leads \& lags=1) } \\
\hline \multirow[t]{2}{*}{$\log ($ investments) } & $0.1532 * * * *$ & $0.1296 * * *$ & 0.0068 \\
\hline & $(0.0309)$ & $(0.0345)$ & $(0.0114)$ \\
\hline \multirow[t]{2}{*}{$\log ($ Gini index $)$} & $-0.1567 * * * *$ & $-0.1700 * * * *$ & $-0.1187 * * * *$ \\
\hline & $(0.0208)$ & $(0.0282)$ & $(0.0069)$ \\
\hline \multicolumn{4}{|l|}{ Panel DSUR (leads \& lags=2) } \\
\hline \multirow[t]{2}{*}{$\log ($ investments $)$} & $0.1841 * * * *$ & $0.0843 * * * *$ & -0.0151 \\
\hline & $(0.0132)$ & $(0.0168)$ & $(0.0092)$ \\
\hline \multirow[t]{2}{*}{$\log ($ Gini index $)$} & $-0.1337 * * * *$ & $-0.1622 * * * *$ & $-0.1216 * * * *$ \\
\hline & $(0.0132)$ & $(0.0168)$ & $(0.0071)$ \\
\hline countries & 7 & 6 & 11 \\
\hline years & 34 & 34 & 34 \\
\hline observations & 238 & 204 & 374 \\
\hline
\end{tabular}


DSUR is used. So, it seems that the positive long-run growth elasticity of income inequality presented in table 6 probably resulted from bias in the DOLS estimator.

\section{Conclusions}

The results show that the distribution of income and economic development seem to have a steady-state equilibrium relation, or relations, as commonly predicted by theoretical models. The results also show that this long-run growth elasticity of income inequality is negative in all income groups. Results imply that there are no major differences in the effect of income inequality on growth at the different stages of economic development. This may result from globalization, i.e. from the removal of barriers of trade and capital flows. Modern developing economies do not need to accumulate capital through greater aggregate savings. Capital and skill-biased technologies are instead imported, and developing countries can concentrate on maximizing the accumulation of human capital through more equal income distribution.

There are three reservations that have to be attached to the results: the highly simplified production function, the time dimension, and the extent of the data used in estimation. The production function used in estimation included only two inputs, namely physical capital and income inequality. It was assumed that the coefficient of inequality reflects the effect of human capital on production growth. However, it is likely that the observed effect of income inequality reflects the economic effects of several other variables as well. It has been shown that income inequality may, in addition to human capital, have an effect on several variables, e.g. social capital, aggregate savings, and social stability. Controlling for all these variables could result in biased coefficient of inequality, because the coefficient would not represent the aggregate effect of income inequality but only a partial 
effect. Thus, it may be feasible not to try to control the different channels through which income inequality may affect growth.

Panel cointegration methods have made it possible to test for cointegration using only a handful of time series obsevations. This has brought about a dilemma. If only a few dozen time series observations are needed for cointegration testing, what is the time dimension after which the relationship can be described as a longrun relation? It was assumed here that a "lower bound" for long-run relationship is one generation (25 to 30 yearly observations). Some may argue that, economically, this does not constitute long-run. However, theories describing the effect of inequality on growth predict that there may be temporary steady-state equilibria between them at different stages of economic development. As results presented here indicate that countries in question seem to be, at least, in their temporary steady-state equilibria within this period, it seems that one generation could be considered long-run in this setting.

The dataset used in estimation was fairly small including only 38 countries at maximum. There were also only few less developed countries included in grouprelated estimations. Due to this, the results of less developed economies should be taken cautiously, but the data on rich countries was far more comprehensive. In rich economies, estimation results validated the general finding of the theories describing the relationship between income inequality and growth. That is, income inequality is associated with lower long-run economic growth in rich economies. 


\section{REFERENCES}

Atkinson, Anthony and Brandolini, Andrea (2001): Promise and pitfalls in the use of secondary data-sets: Income inequality in OECD countries as a case study. Journal of Economic Literature, 34, pp. 771-99.

Arellano, Manuel and Bond, Stephen (1991). Some test of specification for panel data: Monte Carlo evidence and an application to employment equations. Review of Economic Studies, 58, pp. 277 - 97.

Baltagi, Badi H. (2008). Econometric Analysis of Panel Data. West Sussex: John Wiley and Sons Ltd.

Banerjee, Anindya, Marcellino, Massimiliano and Osbat, Chiara (2005): Testing for PPP: Should we use panel methods? Empirical Economics, 30, pp. 77-91.

Banerjee, Anindya, Marcellino, Massimiliano and Osbat, Chiara (2004). Some cautions on the use of panel methods for integrated series of panel data. Econometrics Journal, 7, pp. 322-40.

Banerjee, AbhiJtt and Duflo, Esther (2003). Inequality and growth: What can the data say? Journal of Economic Growth, 8, pp. 267-99.

BArro, Robert (2000). Inequality and growth in a panel of countries. Journal of Economic Growth, 5, pp. 5-32.

Barro, Robert and Lee, Jong-Wha (2000). International data on educational attainment: Updates and implications. CID working paper no. 42.

BÉnabou, Roland (2005). Inequality, technology, and the social contract in Philippe Aghion and Steven Durlauf, eds., Handbook of Economic Growth 1B. NorthHolland. 
BÉnabou, Roland (1996). Inequality and growth, in Ben S. Bernanke and Julio J. Rotemberg, eds., NBER macroeconomics annual. Cambridge, MA: MIT Press.

Benhabib, Jess and Rustichini, Aldo (1996). Social conflict and growth. Journal of Economic Growth, 1, pp. 125-42.

BreITUNG, Joerg (2005). A parametric approach to estimation of cointegrating vectors in panel data. Econometric Reviews, 24, pp. 151-73.

Bourguignon, Francois (1981). Pareto superiority of unegalitarian equilibria in Stiglitz' model of wealth distribution with convex savings function. Econometrica, 49, pp. 1469-75.

Chen, Been-Lon (2003). An inverted-U relationship between inequality and longrun growth. Economics Letters, 78, pp. 205-12.

Сног, IN (2002). Instrumental variables estimation of a nearly nonstationary, heterogenous error component model. Journal of Econometrics, 109, pp. 1-32.

De La Croix, David and Doepke, Matthias (2003). Inequality and growth: Why differential fertility matters. The American Economic Review, 93, pp. 1091113.

Deininger, Klaus and Squire, Lyn (1996). A new data set measuring income inequality. World Bank Economic Review, 10, pp. 565-91.

Dynan, Karen,Skinner, Jonathan, and Zeldes, Stephen (2004). Do rich save more? Journal of Political Economy, 112, pp. 397-444.

Easterly, William and Sewadeh, Mirvat (2002). Global Development Network Growth Database, World Bank. http://www.worldbank.org/research/growth/GDNdata.htm). March 2007. 
Fishman, Arthur and Simhon, Avi (2002). The division of labor, inequality and growth. Journal of Economic Growth, 7, pp.117-36.

Forbes, Kristin J. (2000). A reassessment of the relationship between inequality and growth. The American Economic Review, 4, pp. 869-87.

Frazer, GARTH (2006). Inequality and development across and within countries. World Development, 34, pp. 1459-81.

Föster, Michael and Pearson, Mark (2002). Income distribution and poverty in the OECD area: Trends and driving forces. OECD, Economic Studies, 34. http://www.oecd.org/dataoecd/16/33/2968109.pdf. January 2005.

Galbraith, James K. and Kum, Hyunsub (2006). Estimating the inequality of household incomes: A statistical approach to the creation of a dense and consistent global data set. UTIP working paper no. 22. http://utip.gov.utexas.edu. January 2007.

Galor, Oded and Moav, OMer (2004). From Physical to human capital accumulation: Inequality and the process of development. Review of Economic Studies, 71, pp. 1001-26.

Galor, Oded and ZeIRA, JosePh (1993). Income distribution and macroeconomics. The Review of Economic Studies, 60, pp. 35-52.

Heston, Alan , Summers, Robert and Aten, Bettina (2006). Penn World Table Version 6.2. Center for International Comparisons of Production, Income and Prices. University of Pennsylvania. December 2007.

Hsiao, Cheng (2003). Analysis of Panel Data. New York: Cambridge University Press. 
Im, Kyung So, Pesaran, Hashem M. and Shin, Yongcheol (2003). Testing for unit roots in heteregenous panels. Journal of Econometrics, 115, pp. 53-74.

Kao, Chinwa and Chiang, Min-Hsien (2000). On the estimation and inference of a cointegrated regression panel data. Advances in Econometrics, 15, pp. 179-22.

Kaldor, Nicholas (1957). A model of economic growth. The Economic Journal, 67, pp. 591-624.

Krugman, Paul (2008). The Return of Depression Economics and the Crisis of 2008. London: Penguin Books Ltd.

Kuznets, Simon (1955). Economic growth and income inequality. American Economic Review, 45, pp. 1-29.

Levin, Andrew, Lin, Chien-Fu, and Chu Chia-Shang James (2002). Unit root tests in panel data: Asymptotic and finite-sample properties. Journal of Econometrics, 108, pp. 1-24.

Li, Hongyi and Heng-Fu, Zou (1998). Income inequality is not harmful for growth: Theory and evidence. Review of Development Economics, 2, pp. 318-34.

Lin, Shu-Chin, Huang, Ho-Chuan and Weng, Hsio-Weng (2006). A semi-parametric partially linear investigation of the Kuznets' hypothesis. Journal of Comparative Economics, 34, pp. 634-47.

Maddala, G.S. and Wu, Shaowen (1999). A comparative study of unit root tests with panel data and a new simple test. Oxford Bulletin of Economics and statistics, special issue, pp. 631-52.

Mark, Nelson C., Ogaki, Masao and Sul, Donggyu (2005). Dynamic seemingly unrelated cointegrating regressions. The Review of Economic Studies, 72, pp. 797-820. 
Mark, Nelson C. and Sul, Dongguy (2003). Cointegration vector estimation by panel DOLS and long-run money demand. Oxford Bulletin of Economics and Statistics, 65, pp. 655-80.

Merton, Robert K. (1938). Social structure and anomie. American sociological review, 3, pp. 672-95.

Pedroni, Peter (2004). Panel cointegration: Asymptotic and finite sample properties of pooled time series tests with an application to PPP hypothesis. Econometric Theory, 20, pp. 597-625.

Pedroni, Peter (2000). Fully modified OLS for heterogenous cointegrated panels. Advances in Econometrics, 15, pp. 93-130.

Perotti, Roberto (1993). Political equilibrium, income distribution and growth. The Review of Economic Studies, 60, pp. 755-76.

Persson, Torsten and Tabellini, Guido (1994). Is inequality harmful for growth. American Economic Review, 84, pp. 600-21.

Phillips, Peter C. B. (1987). Towards unified asymptotic theory for autoregression. Biometrika, 74, pp. 535-47.

Phillips, Peter C. B. and Moon, Hyungsik R. (1999). Linear regression limit theory for nonstationary panel data. Econometrica, 67(5), pp. 1057-11.

Phillips, Peter C. B. and Ouliaris, S. (1990). Asymptotic properties of residual based tests for cointegration. Econometrica, 58, pp. 165-93.

Shaw, Clifford and McKay, Henry (1969). Juvenile delinquency and urban areas. Chicago: The University of Chicago Press.

Smith, Adam (1776). An Inquiry Into the Nature and Causes of Wealth of Nations. London. 
Stiglitz, Joseph (1969). Distribution of income and wealth among individuals. Econometrica, 37, pp. 382-97.

Wagner, Martin and Hlouskova, Jaroslav (2007). The performance of panel cointegration methods: Results from a large scale simulation study. Institute for Advanced Studies, working paper.

http://www.ihs.ac.at/publications/eco/es-210.pdf. November 2008. 


\section{APPENDIX}

\section{Appendix A: Bourguignon's (1981) version of Stiglitz's (1969) model of in- come distribution and wealth}

In the model, labor is assumed to be homogenous, and the members of each group have the same income and wealth. Wealth stays within a group between generations and inheritance are equally divided among heirs. Groups differ in their wealth. Each factor is paid by marginal product and production function is assumed to have constant returns to scale and it is assumed to satisfy the Inada conditions. Capital is privately owned. Output per capita, $y$, is defined by

$$
y=f(k), f^{\prime}(k)>0, f^{\prime \prime}<0
$$

where $k$ is the aggregate capital-labour ratio.

$$
r=f^{\prime}(k), w=f(k)-k f^{\prime}(k)
$$

where $w$ is the wage rate and $r$ is the interest rate. When $c_{i}$ is the consumption per capita,

$$
y_{i}=w+r c_{i}
$$

The groups, $m$, grow at he same rate, $n$ and they therefore have a constant weight in the population, $a_{i}$. Thus, when capital is privatively owned:

$$
k=\Sigma_{i=1}^{m} a_{i} c_{i}
$$

All individuals have the same monotonically increasing savings function, $S(y)$, which is assumed to be convex. Additionally it is assumed that

$$
0<S^{\prime}(y)<1, \quad S^{\prime \prime}(y)>0, \quad S^{\prime}(y) \rightarrow 1, \text { when } \quad y \rightarrow \infty
$$


Combining 14 and 17 we get a differential system

$$
\left\{\begin{array}{l}
\dot{c}_{i}=S\left[f(k)+\left(c_{i}-k\right) f^{\prime}(k)\right]-n c \\
k=\Sigma_{i} a_{i} c_{i}
\end{array}\right.
$$

which defines the dynamic behavior of the economy. When production technology $A(k)$ is defined as

$$
A(k) c^{\prime}(k)+[1-A(k)] c^{\prime \prime}(k)=k,
$$

necessary and sufficient condition for the existence of an unegalitarian equilibrium is:

$$
k^{0}<k *, \quad \inf \left(a_{1}, a_{2}\right) \leqq \bar{A},
$$

where $k^{0}$ is the capital in egalitarian equilibrium. The concavity of $f()$ implies that

$$
f(k)+(c-k) f^{\prime}(k)>f(c) \text { for any }(k, c),
$$

where the left hand side is the income of individuals having the wealth of $c$ when the average wealt of population is $k$. In any of the unegalitarian equilibriums $\left(c^{\prime}\right.$ or $\left.c^{\prime \prime}\right)$ it is also the case that

$$
k^{0}<c^{\prime}(k)<c^{\prime \prime}(k)
$$

According to (22) and (23) unegalitarian equilibrium is Pareto superior to egalitarian equilibrium. 
Appendix B: Country lists

Table 8: Country list I

\begin{tabular}{|c|c|c|c|}
\hline Country & observations & country & observations \\
\hline Australia & 35 & Malaysia & 32 \\
\hline Austria & 37 & Malta & 27 \\
\hline Bangladesh & 21 & Mauritius & 32 \\
\hline Barbados & 28 & Mexico & 30 \\
\hline Belgium & 30 & Netherlands & 37 \\
\hline Bolivia & 30 & New Zealand & 34 \\
\hline Canada & 37 & Nicaragua & 21 \\
\hline Chile & 37 & Norway & 36 \\
\hline Colombia & 37 & Panama & 32 \\
\hline Cyprus & 37 & Papua New Guinea & 20 \\
\hline Denmark & 36 & Philippines & 35 \\
\hline Ecuador & 37 & Portugal & 27 \\
\hline Egypt & 36 & Senegal & 24 \\
\hline El Salvador & 28 & Singapore & 37 \\
\hline Fiji & 23 & Spain & 37 \\
\hline Finland & 36 & Sweden & 37 \\
\hline Germany & 25 & Syrian Arab Republic & 36 \\
\hline Greece & 37 & Taiwan & 25 \\
\hline Hong Kong & 27 & Turkey & 36 \\
\hline Hungary & 30 & UK & 32 \\
\hline India & 37 & USA & 37 \\
\hline Indonesia & 29 & Uruguay & 23 \\
\hline Ireland & 36 & Venezuela & 29 \\
\hline Israel & 34 & & \\
\hline Italy & 32 & & \\
\hline Japan & 37 & & \\
\hline Korea, Republic of & 37 & & \\
\hline Kuwait & 38 & & \\
\hline Macao & 20 & & \\
\hline Madagascar & 22 & & \\
\hline $\mathrm{N}=53$ & & & \\
\hline
\end{tabular}


Table 9: Country list II

\begin{tabular}{|c|c|c|}
\hline Countries (25 years) & Countries (34 years) & Countries (37 years) \\
\hline Australia & Australia & Austria \\
\hline Austria & Austria & Canada \\
\hline Barbados & Canada & Chile \\
\hline Bolivia & Chile & Colombia \\
\hline Canada & Colombia & Ecuador \\
\hline Chile & Denmark & Finland \\
\hline Colombia & Ecuador & Greece \\
\hline Cyprus & Finland & India \\
\hline Denmark & Greece & Japan \\
\hline Ecuador & India & Korea, Republic of \\
\hline Egypt & Ireland & Netherlands \\
\hline Finland & Israel & Singapore \\
\hline Greece & Japan & Spain \\
\hline Hungary & Korea, Republic of & Sweden \\
\hline India & Netherland & United States \\
\hline Indonesia & New Zealand & \\
\hline Ireland & Norway & \\
\hline Israel & Philippines & \\
\hline Italy & Singapore & \\
\hline Japan & Spain & \\
\hline Korea, Republic of & Sweden & \\
\hline Kuwait & Syria & \\
\hline Malaysia & Turkey & \\
\hline Malta & United States & \\
\hline \multicolumn{3}{|l|}{ Mauritius } \\
\hline \multicolumn{3}{|l|}{ Mexico } \\
\hline \multicolumn{3}{|l|}{ Netherlands } \\
\hline \multicolumn{3}{|l|}{ New Zealand } \\
\hline \multicolumn{3}{|l|}{ Norway } \\
\hline \multicolumn{3}{|l|}{ Philippines } \\
\hline \multicolumn{3}{|l|}{ Singapore } \\
\hline \multicolumn{3}{|l|}{ Spain } \\
\hline \multicolumn{3}{|l|}{ Sweden } \\
\hline \multicolumn{3}{|l|}{ Syria } \\
\hline \multicolumn{3}{|l|}{ Turkey } \\
\hline \multicolumn{3}{|l|}{ United Kingdom } \\
\hline \multicolumn{3}{|l|}{ United States } \\
\hline \multicolumn{3}{|l|}{ Venezuela } \\
\hline $\mathrm{N}=38$ & $\mathrm{~N}=24$ & $\mathrm{~N}=15$ \\
\hline
\end{tabular}

